\title{
The Income Distribution Impact of Decarbonization in Greece: an Initial Approach
}

\section{S. Karagianni ${ }^{1} \cdot$ M. Pempetzoglou ${ }^{2}$ (D)}

Received: 7 July 2021 / Accepted: 26 September 2021 / Published online: 31 October 2021 (c) The Author(s), under exclusive licence to Springer Nature Switzerland AG 2021

\begin{abstract}
Greece is one of the first European countries that was committed to decarbonize its energy sector by 2028 in the framework of the European Green Deal. However, this rapid and abrupt phase-out of coal-powered electricity raises concerns over the distributional consequences on the Greek households. The transition to clean technology is associated with higher costs, expected to primarily burden the local economy of the coal-producing areas, while the financial support provided by the Just Transition Mechanism is considered insufficient to deal with the negative socio-economic impacts of the lignite phase-out policy. The environmental policies and economic instruments that have been proposed to mitigate the expected side effects on income distribution are considered to be vague, inadequate, and insufficient. The paper aims to shed light on the-neglected-potential impacts of the delignitization policies on income distribution, at both the trans-European, inter-regional, and intra-regional levels, and suggests that governments and policy makers should not neglect the distributional impacts of the policies they apply.
\end{abstract}

Keywords Income distribution · Decarbonization · European Green Deal · Just Transition Mechanism · Greece

\section{Introduction}

The European Union has long played a leading role in tackling climate change. In the aftermath of its Paris Agreement commitments, the European Commission [6] presented the European Green Deal that set out a roadmap to make Europe the first climate-neutral continent by 2050. In this framework, one of the first priorities set, included the decarbonization of the energy sector and the replacement of conventional fossil fuels, such as coal and lignite, with natural gas and renewable energy sources, mainly wind [21] and solar energy.

Yet, it is a commonplace that striving for a cleaner environment, beyond the beneficial effects, causes significant side effects on the socioeconomic system. In fact, a rapid change in the energy model, without being accompanied by supportive policy measures for the affected

M. Pempetzoglou

mariap@sp.duth.gr

1 Department of Economic Sciences, University of Macedonia, 54636 Thessaloniki, Greece

2 Department of Social Policy, Democritus University of Thrace, 69100 Komotini, Greece 
areas and their population, is bound to degrade economic development and destroy jobs in the areas where power generation stations are located, strengthen migration flows, increase energy prices and intensify energy poverty, deteriorate trade balance, and enhance environmental degradation. All these factors will contribute to widening the gap of income inequality among households.

Although Greece does not bear a heavy burden of responsibility for causing the greenhouse effect, it was one of the first European countries committed to shut down the lignite-run power production by 2028 , while simultaneously increasing the renewables share in the country's total energy consumption to 35\% [13]. This energy shift entails a large cost of adjustment in terms of deteriorating income disparities.

The present study aims to identify the negative consequences that the delignitization policies are expected to have on income distribution among (a) the European and the Greek households, (b) the residents of the areas most affected by decarbonization and the inhabitants of the rest of Greece, and (c) the households residing in the areas where lignite plants are located. In addition, we make an attempt to prove that the policies and the financial support that have been proposed to alleviate the distributional impacts of lignite phase-out are considered vague, inadequate, and insufficient and it is likely that they will open the gap of economic inequalities at the trans-European, inter-regional, and intra-regional levels.

The topic, which is novel in social research on inequalities, has not been studied sufficiently yet. Indeed, although various studies have investigated the effects of decarbonization on specific variables - such as income, production, unemployment, gross value added and aggregate demand $[9,10]$ - there is no research focusing on its distributive effects. In this sense, the paper is considered an initial approach in determining the distributive effects of decarbonization in Greece. The identification of the problem is based on the results of other studies, which are more specialized in determining the changes on specific variables, and applying quantitative methods of analysis, mainly input-output tables. At the present stage of the study, we approach the issue using qualitative methods, basically observation and plausibility probes $[1,14]$. The observation relies on understanding and interpreting the effects of the delignitization policy on income distribution and inequalities at the three levels of analysis, namely the trans-European, the inter-regional, and the intra-regional. The plausibility probes involve the fact that the present paper is a preliminary study on the distributional effects of decarbonization, which will be used to determine whether further examination of the topic is warranted. Our goal is, in a next step, to apply quantitative methods in order to assess the issue not only intuitively, but moreover to quantify the effects of decarbonization policies on income disparities in Greece.

The remainder of the paper is organized as follows. Section 2 provides an overview of the decarbonization policy in Greece. Section 3 assesses the potential income distribution impact of lignite phase-out policies in Greece dividing them into trans-European, inter-regional, and intra-regional levels. Section 4 outlines and evaluates the weaknesses of the projected policies to alleviate the distributional impacts of energy transition and section 5 concludes.

\section{The Decarbonization Policy in Greece}

Greece's power mix has historically relied heavily on coal to satisfy its domestic needs for power generation for more than half a century. There are four important lignite deposits in the country, but only two of them are exploited so far-namely, the West Macedonia (WM) and the Megalopolis region - and they produce some of the cheapest and most 
cost effective kilowatt per hour within the European Community [18]. In 2014, Greece was ranked in the $7^{\text {th }}$ place among the 10 greatest brown coal producers worldwide.

In the lignite-dependent regions of Greece, the regional economy relies solely on energy production and its supporting activities. In the region of WM, where two-thirds of the country's electric power is produced, the Public Power Corporation S.A. (PPC S.A.), the biggest electric power company in Greece, contributes to the creation of almost $50 \%$ of the jobs in the secondary sector [19]; moreover, each of the 5000 jobs at PPC S.A. maintains 3.5-4 indirect jobs in the local labor market. Even during the economic crisis, the electricity sector showed an increase in employment by $54.8 \%$, offsetting the losses and creating a comparative advantage for the region [9]. The high labor productivity of the affected regions is observed solely in the (capital-intensive) mining sector-energy. In the other sectors, there is a significant lag in labor productivity compared to the national average [10]. In addition, the energy sector holds the largest share in the formation of the region's gross value added (33.8\% in 2016). The Greek electricity company has been investing for the latest decades in carbon-intensive infrastructure. And, despite the attempt to completely delignify the area, a new lignite plant is currently under construction (Ptolemaida V), with 2022 as the year of trial operation. Its cost amounts to 1.4 billion $€$ and it was designed to operate with lignite. In 2028, it will be forced either to shut down or to change the fuel mixture, devaluing the existing investment, which will not have sufficient time to be depreciated and, furthermore, additional costs for fuel replacement will be required. In the Megalopolis region, the PPC S.A. started in 1970 with two lignite plants, that became four in 1991. In 2011, the two older units ceased their operation. In 2015, a natural gas unit was constructed; it is the only one that operates nowadays.

The deindustrialization that took place in Greece, due to its accession in the EU, and the severe financial crisis that followed, contributed to the restriction of its GHG emissions; indicatively, as Figure 1 shows, in 2018, the share of $\mathrm{CO}_{2}$ emissions of Greece to the EU-28 total amounted to only $2 \%$.

The Member States with the largest contribution to the total EU hard and brown coal use in 2018 are Germany and Poland; together they consume more than half of the total EU coal and their GHG emissions account for almost one third of the EU's total [17]. And, although, the European Green Deal aims to transform the EU into a resource-efficient economy with no net emissions of greenhouse gases in 2050, in Germany and Poland new or extended coal-fired power plants are under construction [20].

\section{The Income Distribution Impact of Decarbonization}

The lignite phase-out policies are expected to primarily affect the local economy and the standards of living of the people in the coal-producing areas, related to the other regions of the country and consequently the other countries too. The adverse effects on income distribution are bound to be both direct and indirect.

\section{Trans-European Level}

The different time horizons for the implementation of the decarbonization policies between the EU member-countries, without taking into account the factor of each country's contribution to the greenhouse effect, will open the gap of inequalities between the economies. Countries that rush to change their energy model first will incur higher costs 


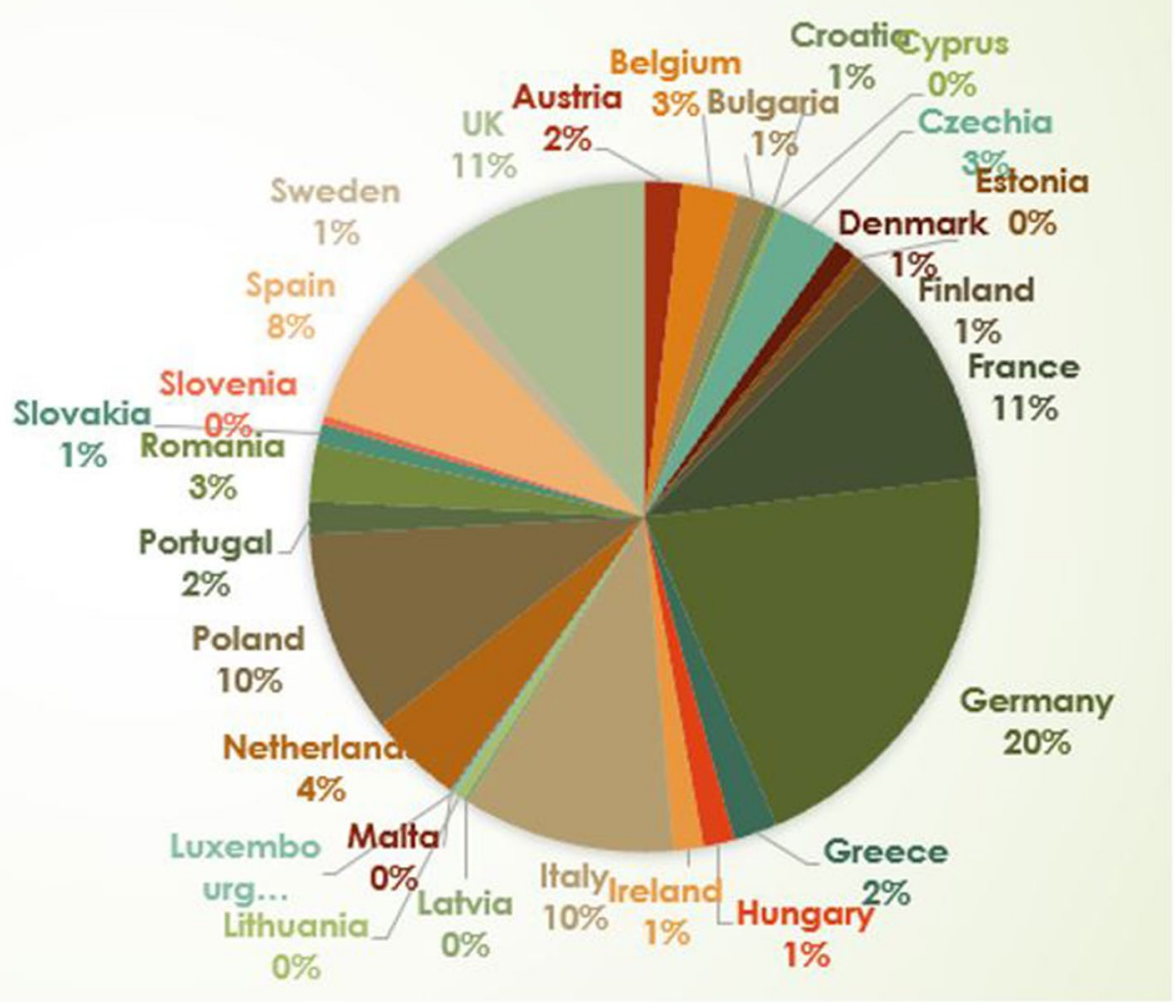

Fig. 1 The share of countries' GHG emissions to the EU-28 total (2018). Source: [8]

of adapting to the new conditions, compared to the countries that have chosen a more gradual transition towards environmentally friendly energy sources.

Greece is a country that, although it has not yet recovered from the financial crisis of 2008 and it is still fighting with the pandemic, was pledged to change its energy model in a very limited time period. Until now, Greece has been exploiting a costless and abundant natural energy source, lignite, for electricity production and it has been investing in carbon-intensive infrastructure. The substitution of lignite combustion with natural gas and renewable energy sources will involve a high cost for replacing the existing mechanical equipment-in order to adapt to the combustion of the new fuel, if and where feasible, the devaluation of the equipment that cannot be replaced and the supply of new natural gas combustion equipment, as well as for constructing and equipping wind and solar parks. Since all this equipment is imported, the country's balance of payments will be deteriorated. Moreover, the country will be obliged to spend a large amount of its foreign exchange reserves on natural gas supply and it will become prone to speculative games in the international financial markets, where the price of natural gas is formed [23]. The dependence on foreign energy sources should not be overlooked for both economic, social, and political reasons, taking, in fact, into account that a domestic input is replaced with an imported one [11]. At the same time, the state transfers ownership 
Table 1 Just Transition Fund allocations by member-state, in million $€$ (in 2018 prices)

\begin{tabular}{|c|c|}
\hline BE & 380 \\
\hline BG & 3 \\
\hline $\mathrm{CZ}$ & 3 \\
\hline DK & 185 \\
\hline $\mathrm{DE}$ & 5 \\
\hline EE & 736 \\
\hline IE & 176 \\
\hline EL & 2 \\
\hline ES & 2 \\
\hline FR & 2 \\
\hline HR & 387 \\
\hline IT & 2 \\
\hline CY & 210 \\
\hline LV & 398 \\
\hline LT & 568 \\
\hline LU & 19 \\
\hline $\mathrm{HU}$ & 543 \\
\hline MT & 48 \\
\hline NL & 1 \\
\hline AT & 282 \\
\hline PL & 8 \\
\hline PT & 465 \\
\hline RO & 4 \\
\hline SI & 538 \\
\hline SK & 954 \\
\hline FI & 968 \\
\hline SE & 324 \\
\hline Total & 40,000 \\
\hline
\end{tabular}

Source: [7].

of electricity generation to the private sector, as foreign private companies are the ones that will undertake the construction and operation of solar and wind parks.

The amounts that will be allocated to Greece through the Just Transition Fund are very limited, and they will hardly cover the cost of replacing the old and acquiring the new equipment; they will certainly be temporary and they will not cover the cost of gas supply which will be extended in perpetuity. Indeed, as Table 1 indicates, Greece, the pioneering country in the European lignite phase-out policy, is planned to receive $4.3 \%$ of the funds, while other countries, as, for example, Germany and Poland-that lead the EU in terms of lignite consumption ${ }^{1}$ - are planning to decarbonize their energy generation systems over a longer period of time-until 2038 and 2050, respectively - and they will, nevertheless, receive $12.9 \%$ and $20 \%$ of the total funds, respectively [23].

Furthermore, the price of energy is expected to increase significantly, exacerbating income inequalities at the trans-European level, for three reasons: (a) the energy

\footnotetext{
${ }^{1}$ Germany and Poland together account for $60 \%$ of the total lignite consumption of the EU (44\% and $16 \%$, respectively). In Greece, the corresponding percentage is $10 \%$.
} 
production will be based on less efficient technologies that produce less energy per unit of time and at a higher cost, compared to other forms of energy production; (b) the purchase cost of the infrastructure construction is significant and it requires to be covered; and (c) the investment should be amortized. Given that electricity prices will remain constant in the other European countries that will follow a slower path of adjustment to the European Green Deal, it is absolutely certain that strong income disparities will arise between the Greek and other European households. Thus, the increase in energy prices will cause adverse distributional effects for the country as a whole, compared to its partner states, in terms of growth prospects, income inequalities, and energy poverty intensification [12]. Specifically, the inflationary pressures will reduce the households' purchasing power as far as goods, energy consumption, and transportation is concerned ${ }^{2}$. Low-income groups spend a large proportion of their income on energy consumption and, due to the lack of savings and access to bank lending, they are unable to make expenditures that will help them adapt to the new conditions and face higher energy costs, for instance by insulating their homes to reduce energy needs or by installing solar water heaters to harness solar energy. To these developments, we should add the boost in unemployment and the wage cuts that took place during the financial crisis period (2010-2014) — where electricity prices increased by 60\%—and the recent coronavirus pandemic.

Income inequality between households may also be intensified due to the competence that will be shaped through the alternative uses of land; for instance, the need for exploiting land for the installation of solar parks instead of cultivations creates competitive conditions in land use and it is estimated that it will push food prices up.

Identically, some activities and industries may be adversely affected, causing a drop in national income and rising unemployment; for example, wind parks can cause drought and change the microclimate of an area (e.g., islands) with significant impacts on economic and tourism activity, since the infrastructure degradates the value of the areas that are being installed. And, certainly, the cost of getting rid of the obsolete "environmentally friendly" equipment, such as wind turbines and photovoltaics, which will burden the economy as well as the environment, should not be neglected; since the service life of the equipment is finite and many of its components are not recycled, there is always the risk of them ending up in the environment ${ }^{3}$ and causing a serious impact on public health, environmental degradation and groundwater contamination, further worsening inequality between Greece and the other European countries, in the sense that, environmental degradation affects human health and burdens the state's budgets with significant health costs and simultaneously incurs budget revenue losses due to poor health quality, widening the budgets' deficit gap between European countries. These negative consequences could be mitigated through the transfer from the linear to a circular economy $[15,16]$.

\footnotetext{
${ }^{2}$ Recall the negative consequences of the 1970s oil crisis, which was due to the rising fuel prices-a major input in all economic activities-which skyrocketed the prices of all products and caused stagflation in many economies.

3 The Waste Electrical and Electronic Equipment (WEEE) directive ([5]/EU) sets the fundamental legal rules and obligation for collecting and recycling photovoltaic panels in the European Union, including setting minimum collection and recovery targets. Up to this day, WEEE does not cover the disposal of solar thermal modules. On the other hand, Europe calls on the wind industry to stop dumping turbine blades, but an institutional framework has not yet been set up [4].
} 


\section{Inter-regional Level}

In 2018, WM, the leading energy-producing area of Greece, held the highest unemployment rate in the country (27\%), while youth unemployment (62\%) was the third highest among the European regions of the EU-28. The region is characterized by three other negative priorities at the national level, namely the percentage of the population exposed to the risk of poverty $(24.8 \%)$, the percentage of underemployed $(18.7 \%)$, and the population density (29.2 inhabitants per $\left.\mathrm{km}^{2}\right)$ [9].

The rapid transformation of the energy model and the reduction of lignite activity will, at first hand, significantly reduce regional income derived from electricity generation and it will boost unemployment in the field of energy production. However, the negative consequences will not be limited to the immediate and self-evident effects. Delignitization is expected to cause significant indirect effects on the regional production and labor market, through activities and synergies related to the power generation sector, i.e., the sectors of metals, machinery, timber, fuel-energy, trade, mining, transport, finance, real estate, and various services. According to the Geotechnical Chamber of Greece - Western Macedonia Branch [9], for every 1 million $€$ drop in the mining sector's final demand (investment or exports), regional production is likely to fall by 1.222 million $€$ (from which 0.222 million $€$ concern other industries), household income by 0.216 million $€$ (from salaries), and employment by 5 jobs. In the Megalopolis region, each position of permanent staff in the electricity generation sector creates and maintains 3.28 jobs in the local labor market and, therefore, decarbonization is expected to directly lead to 1700 lost jobs. Another research, conducted by IOBE-DEI [10], indicates that the fall in employment, due to decarbonization, without any compensatory income support measures, is bound to restrict local households' income in Megalopolis by 80 mil. $€$ annually, which corresponds to $19 \%$ of the local workers' income and, simultaneously, the annual income losses in the rest of the country will amount to 24 mil $€$. The corresponding annual losses of local workers' income in WM amount to 265 mil. $€$, while the income losses for the rest of the country are calculated up to 69 mil. $€$.

If we consider that there is not a single study claiming that the new jobs that will be created in the renewable energy sector will offset the job losses that will result from the lignite-fired plant closures, we shall expect intense migratory flows both inland and abroad and, accordingly, a sharp population decline and a further shrinkage in the working-age population with negative effects on the regional product. High unemployment rates are bound to shrink households' income and worsen the standards of living-both for the energy sector and the synergetic industries' ex-employed. The residents of the peripheries will be forced into early retirement or in search of another job with lower earnings; in any case, this will result in a reduction in their income. Furthermore, the shutdown of mines will create serious environmental and other problems of aesthetic nuisance- provided that there is no provision for the restoration of the surrounding area $^{4}$, which will discourage the installation of commercial or other enterprises [9], making impossible the substitution of older jobs with others in new employment and economic activity branches.

\footnotetext{
4 The cost of land restoration is not negligible; the restoration of the mining activity in the lignite center of Megalopolis alone has been estimated to cost at least $€ 200$ million. In these areas, landscape designers and conservationists should cooperate in order to avoid or reduce the impact of any form of development, consisting the restoration of the landscape of lignite mines, the construction of wind turbines, and the installation of photovoltaics and to offset biodiversity [2].
} 
On the other hand, the energy transition costs in combination with the significantly lower energy efficiency of the renewable energy sources, compared to other forms of energy production, are expected to skyrocket energy prices. Since electricity is characterized by an inelastic demand, due to lack of substitutes, the high energy costs will burden asymmetrically the Greek households that face wage cuts and unemployment, intensifying energy poverty and exacerbating income inequalities between socioeconomic groups within the country [11]. The increase in the price of electricity is inversely progressive towards the base, which means that low-income households will be burdened more than high income households. This is because the cost of electricity covers a large part of the poorest households' budget and an increase in the price of electricity will put an excessive burden on their income. Conversely, wealthier households spend a lower share of their budget on electricity, and an increase in its price will not cause significant losses in their income and consumption.

\section{Intra-regional Level}

Delignitization is expected to create income disparities among the households of the affected areas. The households, whose members were engaged in energy production activities as well as in synergetic industries, will suffer a major blow to their incomes, compared to other households in these regions, widening income inequalities at the intra-regional level. The high unemployment rates and the dimmer job prospects in combination with the increase in energy prices will further widen the income gap between the households of the affected regions and it is likely to disproportionately impact the most vulnerable ones.

As long as this rapid shift from conventional towards cleaner energy does not provide enough time and resources for robust supportive policies, such as financial assistance toward power-generating areas, in the form of creating new jobs, establishing educational programs for training the unemployed that will result from the change in the energy model, funding start-ups etc., the transition will result in significant negative socioeconomic externalities.

\section{Weaknesses of Policies to Alleviate the Distributional Impacts of Energy Transition}

The policies that have been proposed to mitigate the adverse distributional impacts accruing from energy transition seem to be vague, inadequate, and insufficient. To avoid this, there should have been provided a longer adjustment period that would allow the region's workforce to turn to other productive activities as well as a strategic plan for the restructuring of the regional economy and the development of alternative productive activities. At the same time, the state should take into account the adverse distributional effects that will be raised and establish the appropriate redistributive policies to alleviate the most vulnerable socio-economic groups that will be hit by delignitization.

The funds that will be available through the Just Transition Mechanism will not be able to reverse the economic, at first instance, consequences of the lignite phase-out policies, due to the limited time required from the regional economies to adapt to the new conditions and to find solutions in order to retrieve lost jobs. The amounts will be channeled for the replacement of the existing electricity generation equipment with a new one that will 
use natural gas as energy source instead of lignite, as well as the purchase of photovoltaic panels and wind turbines; only a very small portion of the funds will be allocated for the support and adjustment of the local economies and the implementation of social policy. Moreover, the funds will be provided upon conditionality; thus, the authorities will not be able to dispose them at will. Restructuring the economy of the affected areas will not be an easy task and it will require time, funds and political will. There will be a need to provide incentives for developing entrepreneurship; attracting investments; boosting employment; adapting human resources to new skills; upgrading of the health, education, social and cultural infrastructure, land restoration, etc. But, even if all these factors apply, it is doubtful whether this developmental shock will occur. In the past, all the developmental motives and laws, that have been enacted to support these areas, failed to render them business destinations, and, hence, only the energy sector has been able to support the regional economy. Noteworthy is that these regions have been characterized by very low absorption rates of the Partnership Agreement 2014-2020 (ESPA) (less than 19.5\%). Therefore, even if certain amounts are allocated for the reconstruction of the economy, it is more likely that the local community will not take full advantage of them.

Overall, it seems that the policy measures and the funding are not likely to act as compensation to combat the consequences of energy transition and the environmental benefits of lignite phase-out will not be able to offset the losses in terms of income inequality.

\section{Conclusions}

The present paper attempts to conduct an initial investigation on the income distribution impact of delignitization in Greece, using qualitative methods of analysis. The rapid and abrupt energy shift towards a post-lignite era involves a large cost of adjustment and the losses entailed by the substitution of conventional fuels from natural gas and renewables are significantly high. In fact, an accelerated energy transition is likely to shrink regional income, destroy jobs in the energy-generating regions, cause migratory flows, boost energy prices, and deepen energy poverty; that is, in general terms, broaden the gap of income inequality between European and Greek households, among Greek households of different regions and among households residing in the areas where lignite plants are located. As long as this transition is not accompanied by robust financial supportive measures, the negative socioeconomic externalities it entails will be strengthened. Within the European Union, the responsibility of each country, regarding its share on the burden of global pollution, has been neglected and the cost of tackling global warming is being passed on the less developed EU periphery countries, like Greece, which needs to confront an adjustment cost, although it has a small contribution to the greenhouse effect and has been hit hard from the financial crisis and the coronavirus pandemic.

The allocated funds through the European Green Deal's Just Transition Mechanism are insufficient to cover the energy restructuring of the country and the replacement of the abundant and cheap lignite, with imported natural gas, whose price is susceptible to volatility, deteriorates the trade balance, imposes extra costs for the replacement of the electricity generation equipment, and renders the country energy dependent from abroad. Governments and policy makers should be cautious with the policies they adopt, and they should take into account the distributional impacts they imply. There is no doubt that countries should move on to the adoption of more environmentally friendly sources of energy generation and enhance decarbonization through circular economy 
strategies [22], but they should ensure a slow and gradual adjustment, in order to eliminate the gap of income disparities that the decarbonization policy causes to the most vulnerable groups of the society [3].

The results of this preliminary study can serve as a useful guide for further research. Future research can be pursued by conducting quantitative analysis with the use of input-output tables to capture the distributive effects of decarbonization in Greece at all three levels. Distributive concerns should be given the highest priority, in order to enable policy makers evaluate the real costs of the shift towards cleaner energy sources and make the transition more sustainable and acceptable by the local societies.

Abbreviations WM: West Macedonia; PPC S.A: Public Power Corporation S.A.

Data Availability The authors state that data supporting the results reported in the article can be found including, where applicable, hyperlinks to publicly archived datasets analyzed or generated during the study

Code Availability Not applicable

\section{Declarations}

Ethics Approval Not applicable

Consent to Participate Not applicable

Consent for Publication Yes

Conflict of Interest The authors declare no competing interests.

\section{References}

1. Abubakar J (2018) Observational research in the social sciences: a neglected qualitative research technique. Sokoto J Social Sci 8(3):231-240

2. Catalano C, Meslec M, Boileau J et al (2021) Smart sustainable cities of the new millennium: towards design for nature. Circular Economy and Sustainability, forthcoming

3. Chapman R, Boston J (2007) The social implications of decarbonising the New Zealand economy. The Social Policy Journal of New Zealand 31:104-136. https://www.msd.govt.nz/about-msd-andour-work/publications-resources/journals-and-magazines/social-policy-journal/spj31/31-the-socialimplications-of-decarbonising-pages104-136.html. Accessed 17 Mar 2021

4. Craig R (2021) Call for Europe-wide ban on landfilling wind turbine blades, Windpower Monthly, Published: 16 June 2021, https://www.windpowermonthly.com/article/1719408/call-europe-wideban-landfilling-wind-turbine-blades

5. DIRECTIVE 2012/19/EU of the European Parliament and of the Council of 4 July 2012 on waste electrical and electronic equipment (WEEE)

6. European Commission (2019) The European Union continues to lead the global fight against climate change. Press release 11 September 2019 https://ec.europa.eu/commission/presscorner/detail/ en/IP_19_5534

7. European Commission (2020) EU Budget for recovery: questions and answers on the Just Transition Mechanism. https://ec.europa.eu/commission/presscorner/detail/en/qanda_20_931. Accessed 20 Mar 2021

8. European Environment Agency (EEA) (2020) Annual European Union greenhouse gas inventory 1990 - 2018 and inventory report 2020. https://www.eea.europa.eu//publications/european-uniongreenhouse-gas-inventory-2020. Accessed 18 Feb 2021 
9. Geotechnical Chamber of Greece - Western Macedonia Branch (2019) Study for the socio-economic transition of the region of Western Macedonia in the post-lignite period. December 2019. https://drive. google.com/file/d/1H8YavGqY5mo4MPN32-UZ06bDN6m9PnqM/view

10. IOBE-DEI (2020) Fair development transition plan. Delignitization of power generation: socio-economic impact and compensatory actions, August 2020

11. Karagianni S, Pempetzoglou M (2020a) Potential socioeconomic impacts of lignite phase-out policies in Greece. $6^{\text {th }}$ International Symposium on Green Chemistry, Sustainable Development and Circular Economy, Thessaloniki, Greece, 20-23 September

12. Karagianni S, Pempetzoglou M (2020b) Social policy and the environment. In: Sakellaropoulos T, Papatheodorou C (eds) The economics of social policy and the welfare state. Dionikos Publications, Athens

13. Ministry of the Environment and Energy (2019) National Energy and Climate Plan. Athens. https://ec. europa.eu/energy/sites/ener/files/el_final_necp_main_en.pdf. Accessed 5 Mar 2021

14. Mohajan H (2018) Qualitative research methodology in social sciences and related subjects. J Econ Dev Environ People 7(1):23-48

15. Nikolaou IE, Jones N, Stefanakis A (2021) Circular economy and sustainability: the past, the present and the future directions. Circ Econ Sustain 1:1-20

16. Oliveira M, Miguel M, van Langen SK et al (2021) Circular economy and the transition to a sustainable society: integrated assessment methods for a new paradigm. Circ Econ Sustain 1:99-113

17. Olivier JGJ, Peters JAHW (2019) Trends in global $\mathrm{CO}_{2}$ and total greenhouse gas emissions: 2019 report. PBL Netherlands Environmental Assessment Agency, The Hague. https:/www.pbl.nl/sites/ default/files/downloads/pbl-2020-trends-in-global-co2-and-total-greenhouse-gas-emissions-2019report_4068.pdf. Accessed 10 Feb 2021

18. Papanicolaou C, Kotis T, Foscolos A, Goodarzi F (2004) Coals of Greece: a review of properties, uses and future perspectives. Int J Coal Geol 58(3):147-169

19. Rovolis A, Kalimeris P (2016) Roadmap for the transition of the Western Macedonia region to a postlignite era. WWF Greece, Economic \& Technical Assessment. https://www.wwf.gr/images/pdfs/ Roadmap_PostLignite_EN.pdf. Accessed 4 Mar 2020

20. Schearer C (2019) Guest post: How plans for new coal are changing around the world. CarbonBrief, 13 August 2019. https://www.carbonbrief.org/guest-post-how-plans-for-newcoal-are-chang ing-around-the-world

21. Spyridonidou S, Vagiona DGA (2021) Comparative analysis of decision-making methods on site suitability for on- and offshore wind farms: the case of regional unit of Euboea, Greece. Circular Economy and Sustainability, forthcoming

22. Stefanakis AI, Calheiros CS, Nikolaou I (2021) Nature-based solutions as a tool in the new circular economic model for climate change adaptation. Circ Econ Sustain 1:303-318

23. Vatikiotis L (2020) The effects of the transition to the post-lignite era. The case of small and medium enterprises in the Region of Western Macedonia, Research Papers IME GSEBEE, No 11/2020 